Winkler: Thompson'sche Trennungsmethode für Kobalt etc. 109

\title{
XIX.
}

\section{Die Thompson'sche Trennungsmethode für Kobalt und Nickel.}

\author{
Von \\ Clemens Winkler, Hüttenchemiker.
}

Lewis Thomps on spricht sich in einem Artikel über Kobalt (Technologiste, Avril 1863, p. 337 und Polyt. Centralbl. 1863, Lief. XVIII, p. 1223) über die Ungenauigkeit der zeither ïblichen, analytischen Kobalt- Nickeltrennungsmethoden aus, und bringt eine neue Scheidung beider Metalle in Vorschlag, deren Ausführung völlig richtige Resultate geben soll.

Dieselbe besteht in Kürze darin, dass man, nach Abscheidung aller übrigen Metalle, 3 Th. des Gemenges von Kobalt- und Nickeloxydul in geringem Ueberschuss von Salzsäure löst, hierauf $10 \mathrm{Th}$. Chlorcalcium und $10 \mathrm{Th}$. Chlorammoninm zusetzt und die überschüssige Säure (im Wasserbade) verjagt. Das erhaltene, trockne Salzgemenge nimmt man in $150 \mathrm{Th}$. kaltem Wasser auf, und fügt der Lösung 20 Th. anderthalb kohlensaures Ammoniak zu, welches zuvor in 100 Th. kaltem Wasser gelöst worden war. Sodann erhitzt man allmählich zum Sieden, lässt erkalten und absetzen, filtrirt und wäscht mit einer Lösung von kohlensaurem Ammoniak aus. Der Niederschlag soll nur Kobalt, das Filtrat nur Nickel enthalten.

Ich unterwarf die Thompson'sche Angabe einer Prüfung und hielt mich dabei genau an des Verfassers Angaben.

Als Material diente mir ein reines, völlig kobaltfreies Nickeloxydulhydrat und ein Kobaltoxydulhydrat mit dem geringen Gehalte von 0,002 p.C. Nickel. Diese beiden Oxyde setzte ich in verschiedenen Verhältnissen zusammen und suchte dann Kobalt und Nickel nach der Thomps on'schen Methode zu trennen. Es fand augenscheinlich eine Trennung statt; beim Kochen der mit kohlensaurem Ammoniak 
übersättigten Flüssigkeit setzte sich der, vorher gelatinöse Niederschlag zu einem rosenroth gefärbten, krystallinischen Pulver von kohlensaurem Kalk und kohlensaurem Kobaltoxydul zusammen und über demselben blieb eine, je nach der angewendeten Nickelmenge, mehr oder minder blaugefärbte, ammoniakalische Nickellösung stehen. Letztere wurde vorsichtig mit Schwefelnatrium gefällt und die erhaltenen Niederschläge, von denen der eine nickelfreies Kobalt, der andere kobaltfreies Nickel enthalten sollte, mittelst der sehr genauen Probirmethode von Plattner untersucht.

Es zeigte sich, dass die erfolgte Trennung eine nur unvollkommene gewesen sei, und dass namentlich bei vorwiegendem Gehalte an Nickel viel von diesem mit in den Niederschlag gehe.

Als Belege mögen nachstehende, besonders sorgfältig ausgeführte Untersuchungen dienen, welche den Erfolg der Thompson schen Methode bei verschiedenen Verhältnissen von Kobalt zu Nickel zeigen:

Angewendet.

Th.

1) $42,781 \mathrm{Co}$

$9,201 \mathrm{Ni}$

2) 23,429 Co

$25,161 \mathrm{Ni}$

3) $5,896 \mathrm{Co}$

$40,300 \mathrm{Ni}$

Niederschlag.
Th.
$40,424 \mathrm{Co}$
$3,472 \mathrm{Ni}$

17,801 Co $4,910 \mathrm{Ni}$

4,922 Co

$13,444 \mathrm{Ni}$
Gefunden.

$\begin{array}{rr}\begin{array}{c}\text { Lösung. } \\ \text { Th. }\end{array} & \begin{array}{c}\text { Summa. } \\ \text { Th. }\end{array} \\ 2,206 \mathrm{Co} & 42,630 \mathrm{Co} \\ 5,766 \mathrm{Ni} & 9,238 \mathrm{Ni} \\ 5,881 \mathrm{Co} & 23,682 \mathrm{Co} \\ 19,827 \mathrm{Ni} & 24,737 \mathrm{Ni} \\ 0,936 \mathrm{Co} & 5,858 \mathrm{Co} \\ 26,790 \mathrm{Ni} & 40,234 \mathrm{Ni}\end{array}$

Hieraus ergiebt sich, dass Thompson's Methode durchaus keinen Vorzug vor den zeitherigen Verfahrungsweisen habe, sondern, dass dieselbe diesen bei Weitem nachstehe. Doch bleibt die Ausfällung des Kobalts durch kohlensaures Ammoniak, bei Gegenwart von Chlorcalcium, jedenfalls eine interessante Thatsache und für die qualitative Analyse dürfte die von Thompson entdeckte Reaction in vielen Fällen anwendbar sein, wenn man die Fällung mittelst salpetrigsauren Kali's nicht vorziehen will. - 